\section{Family with raised serum alkaline phosphatase activity in the absence of disease}

Idiopathic familial raised serum alkaline phosphatase activity has been reported only once. ${ }^{1}$ The prevalence and nature of this curious biochemical abnormality is unknown. We report results of genetic and isoenzyme studies in another family with this disorder.

\section{Subjects, methods, and results}

A 9-year-old boy was referred to hospital for investigation of abdominal pain. His serum alkaline phosphatase activity was over $1000 \mathrm{U} / 1$. Extensive clinical, radiological, and biochemical investigations failed to account for this. Systematic survey of the whole family (figure) showed that all six siblings of the propositus (aged 8,12,14,16,18, and 21) and his mother had abnormally high serum alkaline phosphatase activities (normal range in our laboratory up to $400 \mathrm{U} / 1$ for children and up to $150 \mathrm{U} / 1$ for adults (Technicon SMA 12/60 method)). Isoenzyme analysis with Gelman Alk-Phos Isozyme electro-

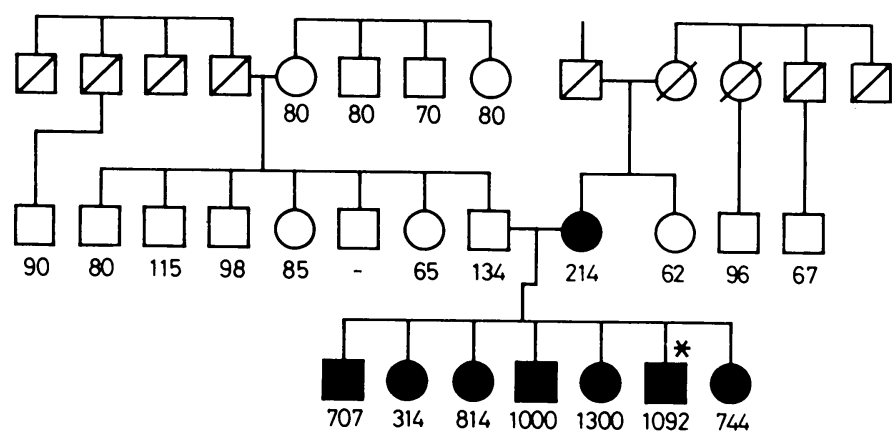

Family tree of propositus $\left(^{*}\right)$ showing serum alkaline phosphatase activities $(\mathrm{U} / \mathrm{l})$ in various members. $\varnothing \square=$ Dead. $\mathbf{\square}=$ Subject with raised activity.

phoresis system showed that the propositus, his siblings, and his mother had an identical isoenzyme pattern, consisting of a slow liver fraction $\left(L_{2}\right)$, a bone fraction, and an intestinal fraction. The approximate proportions of the bone, liver, and intestinal isoenzymes were $75 \%, 10 \%$, and $15 \%$ for the propositus and his siblings, and $40 \%, 35 \%$, and $25 \%$, respectively, for the mother.

One maternal aunt and two maternal uncles had normal total alkaline phosphatase activities but isoenzyme analysis showed a bone fraction as well as the $L_{2}$ liver fraction. Six paternal aunts and uncles available for testing had normal total serum alkaline phosphatase activities but isoenzyme analysis in five showed a bone fraction in addition to the liver $L_{2}$ fraction. No surviving member of the paternal grandparent generation had abnormalities in total alkaline phosphatase activity or in isoenzyme pattern. The maternal grandparent generation could not be investigated because all members were dead. Blood groups in all but one of the investigated members of both sides of the family were $A B$ or $A$, secretor negative; one paternal uncle was group $B$, secretor state unknown.

\section{Comment}

Persistent idiopathic raised alkaline phosphatase activity has been described in two isolated patients by McComb et $a l^{2}$ but no family studies were carried out. A distinct and apparently unrelated condition is idiopathic transient hyperphosphatasia in infancy and childhood. ${ }^{2}$ In the only American family reported by Wilson, ${ }^{1}$ the raised serum alkaline phosphatase activity was due to increases in liver and bone isoenzymes and was inherited in a pattern suggesting an autosomaldominant trait.

Blood groups $A B$ and $A$ and negative secretor state in the present family make the finding of intestinal isoenzyme unexpected, though reports are conflicting. ${ }^{3}$ The mechanism of inheritance in the present family was not clear and further obscured by the presence of intestinal isoenzyme, which is determined by a separate gene locus from the locus (loci) for liver and bone alkaline phosphatases. ${ }^{4}$ Since all the siblings of the propositus were affected, it is possible that both parents were homozygous for the negative mutation of a regulator gene which would result in a recessive gain of function in all offspring. ${ }^{5}$

Awareness of this benign condition should prevent exhaustive investigations once its family nature is established and the family reassured.

We thank Professor J Masterson, department of genetics, University College Dublin, for his advice. We acknowledge financial support from the Irish Cancer Society and the Medical Research Council of Ireland.

${ }^{1}$ Wilson JW. Inherited elevation of alkaline phosphatase activity in the absence of disease. $N$ Engl F Med 1979;301:983-4.

${ }^{2}$ McComb RB, Bowers GN, Posen S. Alkaline phosphatase. New York: Plenum Press, 1979:547, 616.

3 Mössner E, Baier M, Pauly HE, Pfleiderer G. Intestinal alkaline phosphatase in biological fluids: quantitative determination for clinical diagnosis, isolation and characterization. Fresenius Zeitschrift für Analytische Chemie $1980 ; 301: 152-4$.

4 Goldstein DJ, Rogers CE, Harris H. Expression of alkaline phosphatase loci in mammalian tissues. Proc Natl Acad Sci USA 1980;77:2857-60.

${ }^{5}$ Dreyfus J-C. The application of bacterial genetics to the study of human genetic abnormalities. In: Steinberg AG, Bearn AG, eds. Progress in Medical Genetics. Vol 6. London: Heinemann Medical Books, 1969:169200.

(Accepted 11 February 1981)

Endocrine Unit, Mater Misericordiae Hospital, Dublin 7, Ireland

M McEVOY, medical student

P SKRABANEK, LAH, PHD, research investigator

E WRIGHT, FIMLS, chief technologist

D POWELL, MD, FRCPI, consultant endocrinologist

Paediatric Department, Sligo General Hospital, Sligo, Ireland B MCDONAGH, DCH, FRCPI, consultant paediatrician

\section{Raised plasma renin activity in the hypertension of the Guillain-Barré syndrome}

Hypertension has often been observed in patients with the GuillainBarré syndrome, and various underlying mechanisms have been implicated. We report on a child with the Guillain-Barré syndrome whose hypertension was related to increased renin-angiotension activity. Treatment with propranolol controlled the hypertension effectively and reduced the raised plasma renin activity.

\section{Case report}

A 10-year-old boy had severe headache, trismus, and dysarthria of one week's duration. Vital signs showed a blood pressure of $140 / 100 \mathrm{~mm} \mathrm{Hg}$, pulse 84 beats $/ \mathrm{min}$, respirations $12 / \mathrm{min}$, and temperature $37^{\circ} \mathrm{C}$. Initial examination showed bilateral paresis of the facial nerves, and at this stage no other neurological signs were present. Myasthenia gravis was excluded by failure to respond to edrophonium chloride. Results of laboratory studies showed a normal erythrocyte sedimentation rate, complete blood cell count, electrolyte and serum creatinine concentrations, liver function tests, muscle enzyme activities, heavy-metal screen, and antinuclear antibody tests. Raised IgM concentrations of $420 \mathrm{mg} / 100 \mathrm{ml}$ were found; IgG was 1100 $\mathrm{mg} / 100 \mathrm{ml}$ and $\mathrm{IgA} 130 \mathrm{mg} / 100 \mathrm{ml}$, which are within the normal range. The specific IgM titres for cytomegalovirus were 1:8 within the first week of the disease and undetectable four weeks later. Cultures of urine for the virus were negative. On admission the cerebrospinal fluid had an opening pressure of $11 \mathrm{~cm} \mathrm{H} \mathrm{H}_{2} \mathrm{O}$, protein was $0.2 \mathrm{~g} / \mathrm{l}$, glucose was $3.88 \mathrm{mmol} / 1(70 \mathrm{mg} / 100 \mathrm{ml})$, and no leucocytes were present. Electrocardiography and electroencephalography yielded normal results. Roentgenograms of the skull and chest and an intravenous pyelogram were also normal.

During the next 10 days a gradually progressive ascending symmetrical muscle weakness occurred without any sensory loss. A repeat spinal tap showed a protein content of $3 \mathrm{~g} / 1$ without pleocytosis. Electromyography showed distinct slowing of nerve conduction time and no signs of denervation. These findings confirmed the diagnosis of the Guillain-Barre syndrome. Further deterioration was manifested by progressive paresis of his arms and legs, dysphagia, and a measured vital capacity of $47 \%$ of the expected value. 
Prednisone treatment was started. The figure shows the patient's course of recovery. A relapse occurred after 45 days, which also responded to prednisone.

Before the onset of paresis and throughout the course of the disease diffuse headache was prominent and sometimes debilitating. Chlorothiazide and hydralazine were ineffective in relieving the symptoms. The patient's hypertension and concomitant headache were controlled with propranolol. Plasma renin activity was raised throughout the course (range 13.0-14.8 nmol/1/h $(16.9-19.2 \mathrm{ng} / \mathrm{ml} / \mathrm{h}))$ and eventually returned to normal $(1.5 \mathrm{nmol} / 1 / \mathrm{h}(2.0$ $\mathrm{ng} / \mathrm{ml} / \mathrm{h})$ ) after high doses of propranolol. Serum catecholamine concentration $(150 \mathrm{ng} / \mathrm{ml})$ and urine excretion of vanillylmandelic acid $(<5.0 \mathrm{mg} / \mathrm{g}$ creatinine) were normal. During this period propranolol was stopped for 12 hours and severe headache and hypertension recurred.

Six months after admission the patient had a normal vital capacity and no signs of residual muscle weakness or hypertension.
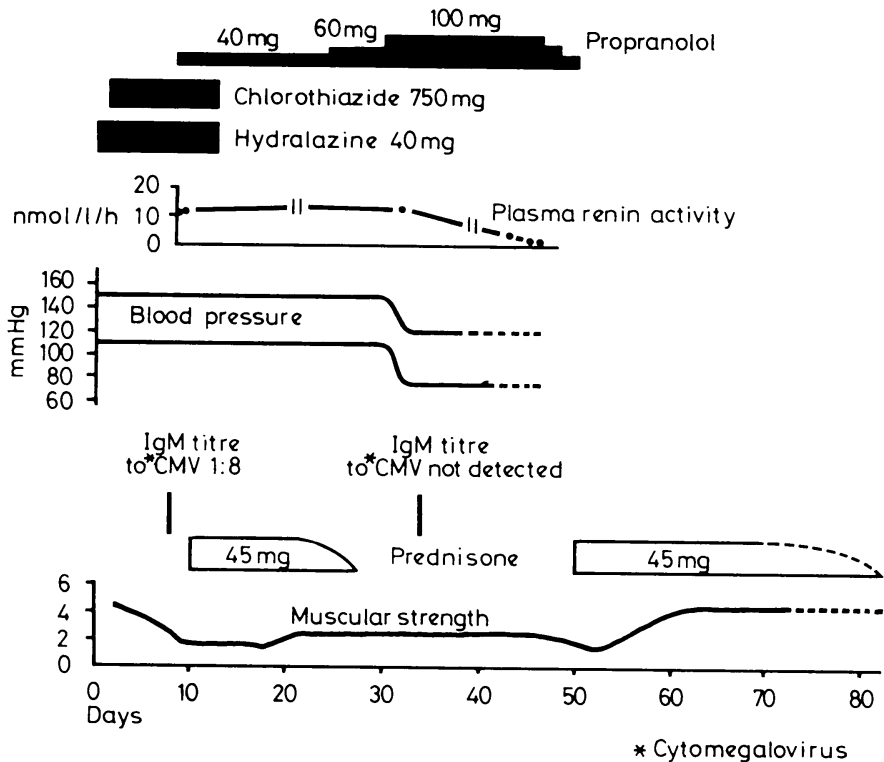

Flow chart of clinical progress and treatment.

Conversion: SI to traditional units-Plasma renin activity: $1 \mathrm{mmol} / 1 / \mathrm{h} \approx 1.3$ $\mathrm{ng} / \mathrm{ml} / \mathrm{h}$.

\section{Comment}

Symptoms related to disease of the autonomic nervous system are common in patients with the Guillain-Barré syndrome. ${ }^{1}$ It is unlikely, however, that adrenergic overactivity was responsible for the hypertension in our patient, since no tachycardia, hyperhidrosis, or peripheral vasoconstriction were noticed. In addition, no raised values of blood catecholamines or urinary excretion of vanillylmandelic acid, as observed by Mitchell and Meilman, ${ }^{2}$ were found. The presence of the hypertension was closely associated with the raised plasma renin activity. Propranolol, which inhibits renin biosynthesis by the juxtaglomerular apparatus, proved particularly effective in controlling the headache and reduced the blood pressure and plasma renin activity. Only one similar case has been reported. ${ }^{3}$

We suggest that plasma renin activity should be measured in all patients with the Guillain-Barré syndrome and hypertension, and that propranolol should be the drug of choice in the hypertension of the Guillain-Barré syndrome.

${ }^{1}$ Lichtenfeld P. Autonomic dysfunction in the Guillain-Barré syndrome. Am $\mathcal{F}$ Med 1971;50:772-80.

${ }^{2}$ Mitchell PL, Meilman E. The mechanism of hypertension in the GuillainBarré syndrome. Am $\mathcal{F}$ Med 1967;42:986-95.

${ }^{3}$ Stapleton FB, Skoglund RR, Daggett RB. Hypertension associated with the Guillain-Barré syndrome. Pediatrics 1978;62:588-90.

(Accepted 13 fanuary 1981)

Department of Paediatrics "B", Chaim Sheba Medical Centre and

Sackler School of Medicine, Tel-Hashomer, Israel

J LAUFER, $M D$, registrar

J PASSWELL, MB, MRCP, consultant paediatrician

G KEREN, MD, senior registrar

$\mathrm{N}$ BRANDT, MD, consultant neurologist

B E COHEN, MB, FRCP, director, department of paediatrics

\section{Serum ferritin and rheumatoid disease}

All inflammatory conditions affect iron kinetics. In rheumatoid arthritis this is reflected by anaemia, with variables suggestive of iron deficiency but normal iron stores within the bone marrow and excess iron within the inflamed synovial membrane. The synovial reticuloendothelial cell stores iron as ferritin ${ }^{1}$ within the protein envelope of apoferritin. The production of ferritin by the reticuloendothelial cell and concomitant rise in serum ferritin concentration may reflect the cell's attempt to protect itself from the toxic consequences of excess free intracellular iron.

Estimation of serum ferritin concentration is useful in assessing the degree of inflammation in juvenile chronic polyarthritis ${ }^{2}$ and in many other inflammatory conditions. Because of suggestions that disturbance of iron metabolism may directly affect the inflammatory process ${ }^{3}$ we studied the role of serum ferritin concentration in patients with rheumatoid synovitis and systemic rheumatoid disease.

\section{Patients, methods, and results}

Serum ferritin concentration was measured by radioimmunoassay (Gammadab ${ }^{125}$ I ferritin kit, Travenol Lab). Two studies were performed: A cross-sectional study of 47 patients with rheumatoid synovitis and 13 with systemic complications of their disease and a longitudinal study of 150 patients presenting with early rheumatoid synovitis (total duration less than six months) and continued for 18 months through exacerbation and remission of their disease. In the first study serum ferritin concentration was correlated with two measures of inflammatory activity: clinical, Ritchie articular index (joint pain index) and duration of morning stiffness; laboratory, haemoglobin concentration, white cell count, platelet count, IgM rheumatoid factor, plasma viscosity, erythrocyte sedimentation rate, C-reactive protein, putative immune complexes ( $\% \mathrm{Clq}$ binding activity), and complement components C3 and C4. There was no significant correlation between serum ferritin concentration and any of these variables (Spearman rank correlation coefficient $r \leqslant 0.2$ in each case). Mean serum ferritin concentration in the 13 patients with systemic complications, however, was three times that in the 47 patients with pure synovitis $(240 v 80 \mu \mathrm{g} / \mathrm{l} ; \mathrm{p}<0.001)$.

In the longitudinal study serum ferritin concentrations were raised during episodes of active synovitis and fell with remission. Changing concentrations mirrored changes in plasma viscosity and levels of circulating immune complexes. High concentrations $(\geqslant 300 \mu \mathrm{g} / \mathrm{l})$ were found in eight out of 10 patients who presented with, or developed, systemic manifestations and severe disease. None of the five patients with low initial concentration $(\leqslant 15 \mu \mathrm{g} / \mathrm{l})$ developed such complications and all had mild disease, often seronegative. A single estimation of serum ferritin concentration was no help in assessing the degree of inflammation unless contrasted with an estimation performed during a period of remission, which accounts for the lack of correlation in the cross-sectional study.

\section{Comment}

Serum ferritin concentrations fluctuate during episodes of inflammation, the percentage change within the individual rather than the absolute concentration reflecting the degree of inflammation. Consequently serum ferritin concentration may be used to monitor inflammatory activity only if serial measurements are made. An initial high concentration in patients presenting with early rheumatoid arthritis is a poor prognostic index associated with either the presence of, or development of, systemic complications and severe disease.

That iron may have a direct role in worsening the inflammatory process is supported by the observations that high ferritin concentrations are associated with systemic disease and that patients with low concentrations do not appear to develop such complications. Iron may promote inflammation by catalysing free oxygen radical production, ${ }^{3}$ which may adversely affect reticuloendothelial metabolism. Genuine iron deficiency reflected by a low serum ferritin concentration may therefore protect against such complications. This may explain why men, with their greater iron stores, are more likely to develop the most severe systemic complications of this disease, which have recently been suggested to be due to reticuloendothelial cell dysfunction. ${ }^{4}$ Intravenous iron infusion in patients with established rheumatoid inflammation may be associated with exacerbation of the disease. ${ }^{5}$

Iron in the development of systemic rheumatoid disease merits further investigation.

1 Muirden KD. Ferritin in synovial cells in patients with rheumatoid arthritis. Ann Rheum Dis 1966;25:387-401.

2 Craft AW, Eastham EJ, Bell JI, Brigham K. Serum ferritin in juvenile chronic polyarthritis. Ann Rheum Dis $1977 ; 36: 271-3$. 